\title{
Estratégias de aprendizagem informal no trabalho utilizadas por gerentes em uma Instituição Financeira Pública
}

\section{Informal learningstrategies at work used by managers in a Public Financial Institution}

\author{
Sergio Santoro ${ }^{l}$ \\ Diógenes de Souza Bido ${ }^{2}$
}

\begin{abstract}
Resumo
Este artigo tem como objetivo geral identificar a relação entre as estratégias de aprendizagem informal no trabalho com o desenvolvimento de competências gerenciais em uma instituição financeira pública. Por conseguinte, três objetivos específicos foram definidos: a) analisar as estratégias de aprendizagem informal no trabalho usadas por gerentes de diferentes áreas de uma mesma instituição financeira pública; b) relacionar tais estratégias de aprendizagem informal no trabalho com o desenvolvimento de competências gerenciais; e c) verificar se gerentes de áreas diversasutilizam as mesmas estratégias de aprendizagem informal no trabalho, resultando no desenvolvimento de competências gerenciais.O tipo de metodologia utilizado foi de caráter qualitativo, de natureza exploratória, realizado em um banco público, tendo como participantes da pesquisa seis gerentes de áreas distintas. A coleta de dados se deu por meio de entrevistas semiestruturadas, que enfatizaram as estratégias de aprendizagem informal no trabalho, procurando relacioná-las com competências gerenciais. Os resultados obtidos indicam que as estratégias de aprendizagem identificadas, como a consulta a materiais de apoio, busca por ajuda interpessoal, aplicação prática, reflexões intrínseca e extrínseca e reprodução estão diretamente ligadas ao aprimoramento de habilidades técnicas, humanas e conceituais em nível gerencial.
\end{abstract}

Palavras-chave: Estratégias de aprendizagem no trabalho. Desenvolvimento de competências gerenciais. Instituição financeira pública.

\begin{abstract}
This paper aims toidentify the relationship between informal learning strategies in the workplace with the development of managerial competencies in a public financial institution. Therefore, three specific objectives have been established: a) to analyze informal learning strategies in the workplace used by managers from different areas in the same public financial institution; b) to relate such informal learning strategies in the workplace with the development of managerial competencies; and c) to verify whether managers from different areas use the same informal learning strategies in the workplace, resulting in the development of managerial competences. The type of methodology used was qualitative, exploratory,and took place in a public bank, having six managers from different areas as the research participants.The data collection was through semi-structured interviews, which focused informal learning strategies in the workplace, aiming to relate them to managerial competencies. The results indicate that the learning strategies identified, such as consulting support materials, searching for interpersonal support, practical application, intrinsic and extrinsic reflections, and reproduction are directly linked to the enhancement of technical, human, and conceptual skills at management level.
\end{abstract}

Key-words: Learning strategies in the workplace. Development of managerial competences.Public financial institution.

1Mestre em Adm. de Empresas pela Universidade Presbiteriana Mackenzie e Doutorando pela Universidade de Coimbra/Portugal E-mail: sergio.santoro100@gmail.com

2 Doutor em Adm. de empresa pela FEA/USP E-mail: diogenesbido@yahoo.com.br

Artigo recebido em: 23 de maio de 2017. Artigo aceito em 29 de junho de 2017. 


\section{Introdução}

As organizações modernas têm buscado, continuamente, melhorias em sua competitividade para atuar de forma eficiente e eficaz em um mercado cada vez mais dinâmico. Embora a aprendizagem nas organizações seja frequentemente associada a processos de treinamento e desenvolvimento, existem outros mecanismos que promovem o desenvolvimento de competências, que não são ações formais de aprendizagem (FREITAS; BRANDÃO, 2006; LE BOTERF, 1999).

As estratégias informais de aprendizagem no trabalho podem ser compreendidas como práticas que as pessoas utilizam para auxiliar na aquisição de conhecimentos em determinado contexto profissional (HOLMAN et al., 2001).

As estratégias formais, de um modo geral, são planejadas pela empresa, enquanto as estratégias informais são utilizadas pelas pessoas como uma forma de resolverem algum problema mais imediato, assim, buscam ajuda interpessoal, ajuda em material escrito, atuam por tentativa e erro (aplicação prática) ou reproduzem a forma que os colegas agem em um processo ou situação.

No Brasil, já foram realizadas algumas pesquisas, predominantemente quantitativas, sobre a intensidade de uso e a sequência de uso dessas estratégias, em funções como: operários da indústria automotiva (USHIRO; BIDO, 2014), enfermeiros e técnicos em enfermagem (CONTE; BIDO; GODOY, 2011); Pantoja e BorgesAndrade (2009) estudaram dezesseis ocupações profissionais (programador, pesquisador, frentista de posto de gasolina, garçom etc.), assim, a presente pesquisa complementa as anteriores, porque busca um entendimento mais profundo desses mecanismos ao analisá-los de modo qualitativo, além de focar o nível gerencial.

O desenvolvimento de competências, por sua vez, acontece por meio da aprendizagem, quer de forma natural, formal ou informal (SONNENTAG; NIESSEN; OHLY, 2004). Durand (2000) relaciona a aprendizagem com a aquisição de conhecimentos, habilidades e atitudes. De acordo com essa compreensão, Brandão e Borges-Andrade (2007) argumentam que esses elementos podem ser considerados propriedades do indivíduo, ou seja, fatores que influenciam o comportamento no trabalho.

A questão que orientou a execução da presente pesquisa foi: Qual é a relação entre as estratégias de aprendizagem informal no trabalho com o desenvolvimento de 
competências gerenciais em uma instituição financeira pública?

Este artigo propõe-se a identificar a relação entre as estratégias de aprendizagem informal no trabalho com o desenvolvimento de competências gerenciais em uma instituição financeira pública.

Por conseguinte, três objetivos específicos foram definidos: a) analisar as estratégias de aprendizagem informal no trabalho usadas por gerentes de diferentes áreas de uma mesma instituição financeira pública; b) relacionar tais estratégias de aprendizagem informal no trabalho com o desenvolvimento de competências gerenciais; e c) verificar se gerentes de áreas distintas utilizam as mesmas estratégias de aprendizagem informal no trabalho, resultando no desenvolvimento de competências gerenciais.

Considerando-se uma perspectiva prática, é relevante examinar se as características individuais dos empregados - por exemplo, estratégias de aprendizagem informal no trabalho - e sua relação para o desenvolvimento de competências gerenciais contribuem para a geração de resultado e desempenho organizacionais, permitindo, assim, às organizações criar e desenvolver um ambiente favorável à aprendizagem.

Este artigo está organizado em mais cinco seções. Na seção seguinte, destacamse os autores que contribuem para a elaboração da fundamentação teórica. Em seguida, na terceira seção, o leitor é informado a respeito da metodologia usada na pesquisa de campo, assim como de uma breve descrição da empresa onde o estudo foi realizado e dos participantes envolvidos. Na seção 4, é apresentada a análise dos resultados. Por último, nas considerações finais, faz-se o fechamento do trabalho, observando-se as principais estratégias de aprendizagem informal no trabalho e sua relação com o desenvolvimento de competências gerenciais.

\section{FUNDAMENTAÇÃO TEÓRICA}

Nesta seção são definidos os conceitos de estratégias de aprendizagem informal no local de trabalho, competências gerenciais e desenvolvimento de competências gerenciais.

\subsection{Estratégias de Aprendizagem Informal no Local de Trabalho}

As estratégias de aprendizagem foram citadas por Rigney (1978) como operações e procedimentos cognitivos utilizados para adquirir, reter e recuperar 
diferentes tipos de conhecimento e desempenho.

Gagné (1980) descreve as estratégias de aprendizagem como capacidades internamente organizadas que orientam a aprendizagem e, quando aprimoradas, qualificam o indivíduo como autoaprendiz. Ambos os autores restringiram o conceito às estratégias cognitivas e relativas às atividades internas.

De acordo com Warr e Bunce (1995), estratégias de aprendizagem são atividades de processamento de informações, usadas pelos aprendizes no momento da codificação, com o propósito de facilitar a aquisição, armazenagem e consequente recuperação da informação aprendida (MENDES; VIEIRA; OLIVA, 2015). Pozo (1999) definiu as estratégias de aprendizagem como procedimentos que se aplicam, de maneira controlada, dentro de um plano projetado deliberadamente, com o objetivo de alcançar uma meta fixada.

Warr e Downing (2000) incluíram na definição de estratégias de aprendizagem: atividades manifestas (processos comportamentais) e não observáveis (processos cognitivos e afetivos), que apresentam variação entre indivíduos e ambientes de aprendizagem e que são relevantes para aperfeiçoar os processos de aprendizagem humana no trabalho. Além disso, Warr e Downing (2000) citam as estratégias de aprendizagem autorregulatórias, que incluem o controle emocional, o controle da motivação e o monitoramento da compreensão. As estratégias de aprendizagem no trabalho podem ser compreendidas como práticas que as pessoas utilizam para auxiliar a aquisição de conhecimento em determinado contexto profissional (HOLMAN et al., 2001).

De acordo com Pantoja e Borges-Andrade (2009), não obstante a existência de diferentes definições, as estratégias de aprendizagem envolvem três importantes aspectos: a) compreendem atividades de processamento de informações facilitadoras da aquisição, retenção, recuperação e uso posterior de novas informações; b) englobam ainda comportamentos empreendidos pelo indivíduo direcionados à aprendizagem e utilização de novos conhecimentos e habilidades; e c) o uso das estratégias de aprendizagem pode contribuir tanto para a aquisição, retenção e recuperação das novas informações como também para a sua aplicação em diferentes contextos.

Segundo Pantoja e Borges-Andrade (2009), as pessoas podem aprender no próprio ambiente de trabalho, por meio de orientações recebidas de superiores e colegas, de observações que fazem acerca do comportamento dos outros no trabalho e da 
reflexão sobre as consequências do seu próprio comportamento. Em decorrência, parecem úteis e oportunas as proposições teóricas e investigações empíricas a respeito das relações existentes entre as características da organização e as estratégias adotadas por seus empregados para aprender em seu dia a dia de trabalho (PANTOJA; BORGESANDRADE, 2009).

Holman et al. (2001) validaram uma escala de estratégias de aprendizagem em um contexto de trabalho, junto a funcionários do call center de um banco britânico. Seus resultados encontraram as categorias relacionadas a seguir, sendo que as três primeiras constituem estratégias de aprendizagem cognitivas, enquanto as três últimas estão relacionadas a estratégias comportamentais - a) reprodução: repetição mental da informação, sem reflexão sobre seu significado; b) reflexão intrínseca: reflexão acerca das relações existentes entre as partes componentes do trabalho; c) reflexão extrínseca: reflexão a respeito das relações entre o trabalho e diferentes aspectos da organização; d) procura de ajuda interpessoal: busca ativa do auxílio de outras pessoas; e) procura de ajuda em material escrito: pesquisa e localização em documentos, manuais, livros e outras fontes não sociais; e f) aplicação prática: tentativa de colocar em prática os próprios conhecimentos enquanto aprende.

Pantoja (2004) validou no Brasil uma escala de trinta itens sobre estratégias de aprendizagem, em uma amostra de profissionais de diversas ocupações. A autora encontrou cinco categorias distintas de estratégias, agrupando em um único fator os itens relativos às estratégias aplicação prática e reflexão intrínseca. Os demais fatores mantiveram semelhança com aqueles originalmente encontrados por Holman et al. (2001).

Os resultados obtidos por Pantoja (2004) forneceram evidências de que existem diferenças, em termos da configuração das estratégias de aprendizagem, em cada uma das categorias profissionais consideradas no seu estudo. Além disso, mostraram o papel central das estratégias comportamentais, mais especificamente da estratégia aplicação prática, nos processos de aprendizagem informal, em ambientes organizacionais. Entre as principais contribuições de seu estudo está o fato das estratégias de aprendizagem no trabalho, mapeadas em diferentes ocupações brasileiras, darem suporte à classificação de Warr e Allan (1998) e aos resultados empíricos de Holman et al. (2001).

Partindo de pesquisa qualitativa, Antonello (2011) chegou a doze categorias ou estratégias de aprendizagem utilizadas por gestores no desenvolvimento de suas 
competências(Quadro 1).

Quadro 1: Categorias de aprendizagem utilizadas por gestores

\begin{tabular}{|c|c|}
\hline $\begin{array}{l}\text { Categorias de } \\
\text { Aprendizagem }\end{array}$ & Definição \\
\hline $\begin{array}{l}\text { Experiência anterior e } \\
\text { transferência } \\
\text { extraprofissional }\end{array}$ & $\begin{array}{l}\text { Transferência de aprendizagem de ocupação/cargo anterior e aprendizagem } \\
\text { fora do trabalho, por exemplo, trabalho voluntário. }\end{array}$ \\
\hline Experenciar & $\begin{array}{l}\text { Experiências amplas (requerem múltiplas habilidades e compreensão global) e } \\
\text { experiências multifacetadas (requerem conexão entre diversas áreas de } \\
\text { conhecimento), atividades pioneiras e de inovação, experiências traumáticas } \\
\text { advindas de situações difíceis e processos de mudança organizacional, por } \\
\text { exemplo, reestruturação ou fusão. }\end{array}$ \\
\hline Reflexão & $\begin{array}{l}\text { Reflexão sobre a ação (após atividade ou evento), reflexão na ação (durante } \\
\text { uma atividade ou evento), reflexão em grupo/coletiva, questionamento e } \\
\text { aprendizagem oriunda do fracasso. }\end{array}$ \\
\hline Autoanálise & Referindo-se à autoanálise e à autoavaliação. \\
\hline Observação-modelo & $\begin{array}{l}\text { Observação estruturada e crítica dos outros, observação informal/casual dos } \\
\text { outros, modelo de papel positivo, ou seja, tentar fazer algo como alguém faz, } \\
\text { modelo negativo de papel, isto é, esforço para não fazer como alguém faz. }\end{array}$ \\
\hline Feedback & $\begin{array}{l}\text { Feedback oriundo de sua equipe de trabalho, crítica de pares de trabalho, } \\
\text { avaliação de desempenho formal por pares/colegas/superiores, escuta eficiente } \\
\text { para o que é dito sobre o desempenho, feedback oriundo de clientes e de } \\
\text { outros profissionais e leitura da linguagem do corpo (como as pessoas reagem } \\
\text { a você). }\end{array}$ \\
\hline $\begin{array}{l}\text { Mudança de } \\
\text { perspectiva }\end{array}$ & $\begin{array}{l}\text { Mudança de papel, transferência/troca de trabalho, trabalhar com pessoas de } \\
\text { áreas diferentes, trabalhar com diferenças culturais e inspiração súbita ou } \\
\text { insight. }\end{array}$ \\
\hline $\begin{array}{l}\text { Mentoria (mentoring) } \\
\text { e tutoria (coaching) }\end{array}$ & $\begin{array}{l}\text { Ser assistido por um mentor/tutor - mentor (orientador/conselheiro) e tutor } \\
\text { (treinador, que instrui e demonstra). }\end{array}$ \\
\hline $\begin{array}{l}\text { Interação e } \\
\text { colaboração }\end{array}$ & $\begin{array}{l}\text { Trabalho em grupo/equipe, colaboração em projetos, aprendizagem oriunda de } \\
\text { outros profissionais da mesma área, aprendizagem a partir de clientes, trabalho } \\
\text { em equipes multidisciplinares e rede (networking) com outros profissionais da } \\
\text { mesma área. }\end{array}$ \\
\hline Cursos e treinamentos & $\begin{array}{l}\text { Treinamento no trabalho (on the job), rotação de funções (job rotation) e } \\
\text { programa trainee, intensa aprendizagem/intenso treinamento (muito além do } \\
\text { mínimo para um desempenho competente), multiplicação de } \\
\text { treinamentos/cursos. }\end{array}$ \\
\hline
\end{tabular}




\begin{tabular}{|l|l|}
\hline \multicolumn{1}{|c|}{$\begin{array}{c}\text { Categorias de } \\
\text { Aprendizagem }\end{array}$} & \multicolumn{1}{|c|}{ Definição } \\
\hline Informal & $\begin{array}{l}\text { Informal no trabalho (baseada na prática - aprendizagem informal e } \\
\text { comunidade de prática) e informal (em cursos de mestrado e especialização). }\end{array}$ \\
\hline $\begin{array}{l}\text { Aprendizagem pela } \\
\text { articulação entre } \\
\text { teoria e prática }\end{array}$ & $\begin{array}{l}\text { Escrever artigos/relatórios, apresentar conferências, } \\
\text { justificar/defender/explanar ações, trabalhos do curso, simulação durante } \\
\text { curso, trabalho final e dissertação e especialização/mestrado articulados à } \\
\text { aprendizagem baseada no trabalho. }\end{array}$ \\
\hline
\end{tabular}

Fonte: Antonello (20

Para o presente estudo, as classificações das categorias/estratégias de aprendizagem informal no trabalho desenvolvidas por Antonello (2011) e Pantoja (2004) serão utilizadas como pré-categorias, para se fazer a relação com o desenvolvimento de competências gerenciais que são listadas neste trabalho, pois, em seus estudos, ambas são as referências teóricas mais atuais nesse campo do conhecimento.

\subsection{Competências Gerenciais e Desenvolvimento de Competências Gerenciais}

Diversos autores (BRUNO-FARIA; BRANDÃO, 2003; CARBONE et al., 2005; DURAND, 2000; FLEURY; FLEURY, 2001; GONCZI, 1999) consideram conhecimentos, habilidades e atitudes (CHA) como dimensões ou elementos constitutivos da competência.

Segundo Durand (2000), o conhecimento corresponde a uma série de informações assimiladas e estruturadas pelo indivíduo, as quais lhe permitem "entender o mundo", é o saber que o indivíduo acumulou ao longo da vida. Para autores de teorias instrucionais, por exemplo, Bloom, Engelhart, Furst, Hill e Krathwohl (1979) e Gagné, Briggs e Wager (1988), o conhecimento representa algo relacionado à lembrança de ideias ou fenômenos, ou seja, algo armazenado na memória do indivíduo por meio de processos psicológicos de aquisição e interpretação de informações.

A habilidade trata sobre o saber como fazer algo (GAGNÉ et al., 1988). É a capacidade da pessoa de fazer uso produtivo do conhecimento que detém, de instaurar conhecimentos armazenados em sua memória e utilizá-los em uma ação (DURAND, 2000).

De acordo com Bloom et al. (1979), uma definição comum de habilidade é a de que o indivíduo pode buscar, em suas experiências anteriores, conhecimentos e técnicas 
apropriadas para examinar e solucionar um problema qualquer. Durand (2000) explica que a habilidade se refere ao saber como fazer algo em determinado processo (knowhow), enquanto o conhecimento diz respeito ao saber fazer o que e por que fazer (knowwhat e know-why), ou seja, a compreensão do princípio teórico que rege esse processo e o seu propósito.

A atitude pode ser definida como uma predisposição do indivíduo para reagir positiva ou negativamente - a um estímulo (BOWDITCH;BUONO, 1992). A atitude passou a ser valiosa para a organização, pois reflete a disposição do indivíduo em assumir responsabilidades diante de situações complexas e refletir sistematicamente sobre o trabalho (ZARIFIAN, 1996) ou adaptar-se rapidamente em ambientes instáveis, mantendo senso de orientação e de aprendizagem contínua (SPARROW; BOGNANNO, 1994).

Durand (2000) chamou de "querer fazer", isto é, constitui uma propriedade relacionada ao desejo, à disposição, à intenção, que influencia a tendência de a pessoa adotar determinado comportamento. Essas dimensões convergem no sentido de que, falar em competências é se referir ao conjunto dos conhecimentos, habilidades e atitudes aplicados ou demonstrados pelos indivíduos na execução de atividades ou tarefas de interesses da organização, contribuindo com a definição de competência por Durand (2000) e Bruno-Faria e Brandão (2003).

As competências gerenciais são uma categoria importante para o presente estudo, principalmente por causa do pressuposto de que o desempenho do gerente exerce influência sobre as competências ou o desempenho de seus subordinados e, por conseguinte, sobre os resultados organizacionais. Essa categoria de competências tem despertado interesse por parte de teóricos, organizações e pesquisadores (BITENCOURT, 2004; ODERICH, 2005; SPENCER; SPENCER, 1993; SANTOS, 2001, entre outros). Nonaka e Takeuchi (1997) tratam o conhecimento apoiado em aspectos tácitos e explícitos, ou seja, destacam a necessidade de se equilibrar práticas formais e informais para o desenvolvimento da organização e de competências gerenciais.

Segundo Bitencourt (2005), os elementos que se destacam no desenvolvimento de competências podem ser resumidos por meio da verificação dos seguintes fatores: as competências estão associadas ao desenvolvimento de conceitos, habilidades e atitudes; demandam capacitação e se traduzem na capacidade de mobilizar recursos em práticas 
de trabalho; implicam articular recursos e servem de pilar para a busca de melhores desempenhos; produzem questionamento constante e desencadeiam um processo de aprendizagem individual, na qual a responsabilidade maior deve ser atribuída ao próprio indivíduo (autodesenvolvimento); são transferidas e consolidadas por meio do relacionamento com outras pessoas (interação). Cada um desses fatores pode estar combinado com os demais.

Determinadas práticas organizacionais podem incentivar o desenvolvimento de competências, abrangendo todos esses aspectos ou privilegiando alguns deles sobre os restantes. $\mathrm{O}$ fato de a organização estar imersa em uma lógica por competências sugere que: missão, visão, valores e cultura são dinâmicos e refletem um posicionamento da empresa no mercado; a competitividade da organização depende do potencial de desenvolvimento de processos e pessoas; os conhecimentos, habilidades e capacidades constituem-se requisitos para que a empresa tenha a sua vantagem competitiva; a aprendizagem coletiva e organizacional alavancam os processos de mudança (BITENCOURT; MOURA, 2006).

Para Le Boterf (1999), as competências gerenciais necessárias para administrar uma situação profissional complexa são: a) saber agir com pertinência: o profissional deve saber ir além do prescrito, agir em situações imprevistas, tomar iniciativas e decisões, negociar, fazer escolhas, aceitar riscos, reagir às eventualidades e aos problemas, inovar o cotidiano e assumir responsabilidades, saber agir e antecipar incidentes; b) saber mobilizar em um contexto: a competência requer saber agir em situação, ou seja, dominar uma técnica e colocá-la em prática num contexto, que pode ser familiar ou de competitividade e de estresse; c) saber combinar: diante de um problema para resolver ou de um projeto para realizar, deve-se construir uma arquitetura cognitiva particular da competência, em uma combinação de múltiplos ingredientes; d) saber transpor: o profissional não se limita a repetir, ele sabe transpor, ou seja, utiliza novos conhecimentos e habilidades e coloca em prática em contextos distintos. Aprendendo a reconhecer problemas de acordo com o contexto, o profissional será capaz de aprender e de aprender a aprender, isto é, ele saberá não somente resolver um problema em particular, mas várias categorias de problemas e de indicadores de contexto; e) saber aprender e saber aprender a aprender: o profissional faz de sua prática profissional uma oportunidade de criação do saber.

Le Boterf (1999) refere-se ao aprendizado de circuito duplo (double loop 
learning) em que o indivíduo corrige não só a ação, mas a teoria, a lógica subjacente e as premissas que estão na base de suas estratégias de ação; f) saber se engajar: o profissional engajado é capaz de tomar iniciativas e fazer propostas, ele avaliará diferentemente cada situação em função da coragem que tem para enfrentá-las e, por conseguinte, os recursos que está pronto a investir.

Os modelos de competências gerenciais são propostas que apresentam um amplo escopo de reflexões acerca das necessidades de planejamento, desenvolvimento e acompanhamento do perfil e formação gerencial a partir da realidade individual e estratégia competitiva de cada empresa, fato esse que caracteriza uma visão processual (desenvolvimento de competência), diferenciando-se de construtos que priorizam a listagem de atributos que por si só não agregam valor à organização ou às pessoas. A aprendizagem organizacional apresenta-se como uma estratégia que busca aproximar e integrar a competência essencial (core competence) e gerencial (BITENCOURT, 2004).

A abordagem das competências gerenciais centrada exclusivamente em atributos privilegia um modelo genérico, que pode ser aplicado a qualquer organização, apesar das diferenças culturais. A mensuração de atributos é priorizada em detrimento de alternativas para o desenvolvimento por competências (BITENCOURT; MOURA, 2006).

Recentemente, as relações entre aprendizagem e competências foram pesquisadas no contexto de trabalho brasileiro. Por exemplo, Brandão (2009), em um estudo multinível, investigou as relações entre as estratégias de aprendizagem, competências e desempenho de agências de um banco nacional. Com base em sua observação, pressupõe-se que a aprendizagem é o processo por meio do qual o indivíduo adquire ou aperfeiçoa competências, relação essa que obriga as organizações a buscarem alternativas para reduzir a distância "entre o que as pessoas sabem e o que elas precisam saber" (BRANDÃO, 2009, p. 62-63).

Estudos empíricos estrangeiros investigaram as relações entre aprendizagem informal e competências no trabalho. Na Austrália, por exemplo, em pesquisa realizada com gerentes de empresas no ramo da construção civil, Murray (2003) classificou as competências em cinco categorias de aprendizagem: a) aprendizagem não estruturada: baseada na experiência e resulta na aquisição gradual e não planejada de competências; b) aprendizagem estruturada: prescreve a forma como as tarefas devem ser realizadas; c) aprendizagem eficiente: melhoria de desempenho por meio da aprendizagem dirigida; d) 
aprendizagem e agregação de valor: dirigida de acordo com necessidades de inovação, criação de novas práticas como resultado de críticas a procedimentos e crenças anteriores; e e) aprendizagem dinâmica: reflexão e inovação norteiam o desenvolvimento de competências de forma dinâmica e integrada.

Considerando que a literatura revisada sugere as relações entre características individuais, o uso de estratégias de aprendizagem e a expressão de competências no trabalho, confirma-se a importância deste estudo.

\section{METODOLOGIA}

$\mathrm{Na}$ realização da presente investigação, optou-se por uma metodologia de natureza qualitativa interpretativa básica (GODOY, 2006), realizada em uma instituição financeira pública, na cidade de São Paulo.

Considerou-se que, para analisar a relação entre as estratégias de aprendizagem informal no trabalho com o desenvolvimento de competências gerenciais, o método qualitativo oferece subsídios para melhor compreender esses fenômenos (VIEIRA; RIVERA, 2012), por permitir aprofundar reflexões relevantes e inspirar articulações entre esses dois construtos.Além disso, a necessidade de avaliar a perspectiva dos entrevistados, inseridos em uma circunstância específica, reforça a ideia de que a pesquisa qualitativa seja a mais apropriada para o presente estudo.

A coleta de dados deu-se por meio de entrevistas semiestruturadas, cujo roteiro foi desenvolvido a partir do referencial teórico, com questões como: Quando você necessita de informações mais detalhadas sobre o seu trabalho, como você procura agir? Você busca ajuda de seus colegas e/ou de colegas de outras áreas da empresa? Como você aprende novas formas de executar o seu trabalho? Analisando criticamente a execução do seu trabalho, você consegue compreendê-lo melhor? Como? Quando você faz o seu trabalho, você pensa em como ele está relacionado ao negócio e às estratégias da organização? De que forma você organiza suas atividades e tarefas diárias para realizá-las no prazo previsto? Como a atuação das diferentes áreas da organização influencia a execução do seu trabalho? E exemplos, toda vez que for possível.

Foram entrevistados seis gerentes de um banco público. $\mathrm{O}$ foco das entrevistas centrou-se em identificar as estratégias de aprendizagem informal no local de trabalho utilizadas e o desenvolvimento de competências gerenciais. 
Para atingir aquilo que foi proposto nos objetivos do trabalho, foi necessária, além do contato direto com os profissionais, uma busca cuidadosa visando descobrir em suas falas quais os significados atribuídos por eles às suas estratégias de aprendizagem, procurando entender e interpretar os momentos mais significativos e a contribuição desses momentos para a evolução de cada um deles dentro da empresa da qual fazem parte.

\subsection{Contexto}

A empresa na qual a pesquisa foi realizada é uma instituição financeira $100 \%$ pública. A empresa exerce um papel relevante na promoção do desenvolvimento urbano e da justiça social do país, uma vez que prioriza setores como habitação, saneamento básico, infraestrutura e prestação de serviços, contribuindo para melhorar a vida das pessoas, principalmente as de baixa renda.

A admissão de empregados no banco acontece, para cargos efetivos, por meio de concurso público, conforme determina a Constituição Federal do Brasil e o Estatuto do banco. Os concursos são divulgados em editais publicados no Diário Oficial e no site da empresa e têm o objetivo de preencher as vagas disponíveis ou formar cadastro de reserva, observando a ordem de classificação e o prazo de validade.

A carreira administrativa inicia-se com o cargo efetivo denominado Técnico Bancário. A ascensão nos níveis salariais do cargo efetivo ocorre por meio das promoções por antiguidade e merecimento. Além dos cargos efetivos, a empresa possui estrutura de funções gratificadas para o exercício de atividades que extrapolam aquelas previstas para o seu cargo efetivo, e o acesso às funções gratificadas ocorre conforme regras definidas pela empresa, considerando o seu poder para designação e dispensa.

A política de ascensão nas funções gratificadas prevê a realização de processos seletivos internos, de forma a propiciar maior transparência e oportunizar ao quadro funcional o acesso às oportunidades de crescimento profissional. Em suma, para que um empregado possa assumir uma função gerencial, necessariamente terá de iniciar sua carreira administrativa como técnico bancário, ascendendo na hierarquia por meio de promoções por tempo de serviço e merecimento profissional.

O Quadro 2 apresenta o perfil dos seis gerentes que foram entrevistados neste estudo.

Revista Eletrônica Gestão e Serviços v.8, n. 1, pp. 1878-1901, Janeiro/Junho 2017.

ISSN Online: 2177-7284 e-mail: regs@ metodista.br 
Quadro 2: Perfil demográfico dos participantes da pesquisa

\begin{tabular}{|c|c|c|c|c|c|c|}
\hline Entre vistados & Sexo & Idade & \begin{tabular}{|l|} 
Estado Civil \\
\end{tabular} & Função Gerencial & \begin{tabular}{|l|} 
Tempo de Empresa \\
\end{tabular} & Formação Acadêmica \\
\hline G1 & $\mathrm{F}$ & 48 & $\mathrm{C}$ & Gerente Subsídio Jurídico & 25 & $\begin{array}{l}\text { Pós-graduação completa } \\
\text { em Gestão Financeira }\end{array}$ \\
\hline G2 & M & 49 & $S$ & Gerente Pessoa Jurídica & 12 & $\begin{array}{l}\text { Graduação completa em } \\
\text { Engenharia Agronômica }\end{array}$ \\
\hline G3 & $\mathrm{F}$ & 48 & $S$ & Gerente Pessoa Física & 24 & $\begin{array}{c}\text { Pós-graduação completa } \\
\text { em Finanças } \\
\text { Empresariais }\end{array}$ \\
\hline G4 & M & 38 & $\mathrm{~S}$ & Gerente Pessoa Física & 12 & $\begin{array}{c}\text { Graduação completa em } \\
\text { Direito }\end{array}$ \\
\hline G5 & M & 37 & $\mathrm{~S}$ & Gerente de Negócios & 12 & $\begin{array}{c}\text { Graduação completa em } \\
\text { Administração de } \\
\text { Empresas } \\
\end{array}$ \\
\hline G6 & M & 40 & $\mathrm{C}$ & $\begin{array}{c}\text { Gerente de Relacionamento } \\
\text { Empresas }\end{array}$ & 24 & $\begin{array}{c}\text { Graduação completa em } \\
\text { Administração de } \\
\text { Empresas }\end{array}$ \\
\hline \multicolumn{7}{|c|}{$\begin{array}{l}\text { Legenda: } \\
\mathrm{G}=\text { Gerente } \\
\mathrm{M}=\text { Masculino } / \mathrm{F}=\text { Feminino } \\
\mathrm{C}=\text { Casado } / \mathrm{S}=\text { Solteiro }\end{array}$} \\
\hline
\end{tabular}

Fonte: Elaborado pelos autores

O princípio de "saturação" ou de "redundância" (GODOI; MATTOS, 2006) foi utilizado nesta pesquisa para determinação do número de entrevistas realizadas. Foi possível perceber que há uma diferenciação no uso das estratégias de aprendizagem entre gerentes que trabalham em agências bancárias e gerentes que trabalham em departamentos, resultando no desenvolvimento de diferentes competências profissionais.

\subsection{Análise dos Dados}

O conteúdo das entrevistas foi transcrito fidedignamente, tornando-se, assim, uma importante massa constituinte do corpo de dados utilizados para a realização deste trabalho. Coletadas as evidências empíricas, foi usada a análise de conteúdo como procedimento sistemático e objetivo para inferir interpretações das mensagens expressadas em seu âmbito manifesto e latente (BARDIN, 1977).

$\mathrm{Na}$ análise de conteúdo, as categorias são rubricas ou classes que reúnem um grupo de elementos em razão de características comuns. A categorização permite reunir maior número de informações à custa de uma esquematização e assim correlacionar classes de acontecimentos para ordená-los. A categorização representa a passagem dos 
dados brutos a dados organizados (BARDIN, 1977).

\section{ANÁLISE DOS RESULTADOS}

Nesta seção, primeiramente são mostradas as falas relevantes dos entrevistados, em seguida elas são interpretadas a que os autores chegaram, tendo como base a literatura utilizada na fundamentação teórica. A apresentação está organizada seguindo os objetivos específicos propostos na introdução desta pesquisa.

\subsection{As Estratégias de Aprendizagem Informal dos Gestores}

Os participantes contam suas experiências de aprendizagem e discorrem a respeito das estratégias de aprendizagem informal, conforme astranscrições a seguir.

[...] A minha área é única no Brasil, não há nenhum outro departamento no país igual a este onde trabalho, por isso, não posso depender de colegas de trabalho quando tenho dúvidas sobre alguma coisa. Procuro fazer as coisas com base nas minhas experiências anteriores que tive aqui no banco, afinal de contas, são 25 anos de experiência... Há também muita coisa pra ler: informativos, normas, leis novas... Como te disse, meu departamento é único, singular, então tenho que ler tudo pra me manter atualizada. Não posso contar com a ajuda de colegas com funções semelhantes à minha porque as atribuições acabam sendo diferentes. (G1)

[...] Basicamente, eu procuro ajuda de outros gerentes da mesma área, de colegas de trabalho com o mesmo nível hierárquico. Aqui, na agência, temos um 'mensageiro', que serve pra gente trocar mensagens em tempo real com qualquer funcionário do banco. Assim que eu preciso de uma informação mais detalhada, eu procuro me comunicar (através do mensageiro) com outros gerentes que já tenham resolvido problemas similares. Às vezes, essa comunicação entre gerentes de mesma função é feita por telefone ou e-mail [...]. (G2)

[...] Em primeiro lugar, deveríamos consultar normativos e instruções que são disponibilizados pela matriz do banco na intranet da empresa. Mas, muitas vezes, a gente não tem tempo pra ler de forma adequada tudo aquilo que é disponibilizado na Intranet ou o que recebemos por e-mail da matriz. Então, pra gente ganhar tempo, a gente acaba consultando outros pares de mesmo nível hierárquico e que já tenham se atualizado sobre as informações enviadas a todos pela matriz. (G3)

[...] É imprescindível consultar normativos e instruções que a matriz nos disponibiliza na Intranet e nos envia por e-mail. É o jeito certo, mas aqui na agência tudo é muito corrido, tudo é pra ontem, entende?Quando tenho alguma dúvida jurídica, por exemplo,consulto os advogados com quem tenho mais contato ou aquele com acesso 
mais facilitado, entendeu? (G4)

[...] Como sou o único gerente com essa função aqui no departamento, procuro ler muita coisa, leio sempre que posso pra me manter atualizado em relação aos negócios do banco. Checo meus e-mails pra saber se saiu alguma coisa nova que seja relevante pra minha função [...] (G5)

[...] Aqui no departamento é possível consultar os normativos que a Matriz nos envia frequentemente. Então, tento ler o máximo de coisas, tento me manter atualizado. Às vezes, dependendo do caso, se for algo simples, converso com colegas próximos, mas a orientação é no sentido de ler as instruções que chegam da matriz, e é o que procuro fazer sempre que possível. (G6)

Em relação à aprendizagem do uso de novos sistemas e aplicativos de informática, todos os gerentes entrevistados compartilham experiências e estratégias de aprendizagem muito similares. Assim sendo, duas passagens são mencionadas sobre esse aspecto.

Não temos um treinamento formal quando um novo sistema é implementado no banco, infelizmente.Aprendemos conversando um com o outro. Aquele que sabe mais acaba transmitindo o conhecimento para os demais colegas... Acho que o departamento de TI deveria ser mais presente, sabe, estar mais perto dos clientes internos. A gente precisa rever isso [...] (G1)

Os novos sistemas e programas de informática são aprendidos por todos de maneira informal... O departamento de TI é distante das demais áreas do banco, embora haja um Help Desk ativo pra eventuais dúvidas relacionadas à área de tecnologia... Não há nenhum treinamento formal... Há muito retrabalho por puro desconhecimento de novas tecnologias, pois muito do que é aprendido nessa área acontece por meio de tentativa e erro do usuário. Eu procuro, então, consultar colegas de trabalho que estejam mais familiarizados com esses novos sistemas de informática. (G2)

Pode-se verificar que os participantes reconhecem a importância do material escrito (normativos e instruções editados pela organização), porém, devido às pressões do ambiente profissional e à falta de tempo para uma leitura adequada nas agências bancárias investigadas, eles, então, procuram ajuda interpessoal/interação e colaboração, por meio do auxílio de colegas de trabalho com o mesmo nível hierárquico. Além disso, os gerentes entrevistados citam a experiência anterior e o conhecimento adquirido ao longo dos anos de carreira profissional, ou seja, a aplicação prática como uma das estratégias de aprendizagem. Isso corrobora com as afirmações feitas por Pantoja (2004) 
e Antonello (2011). As reflexões intrínseca e extrínseca também são relatadas nas falas dos participantes, conforme transcrições a seguir.

[...] Acho importantíssimo pensar no que se está fazendo. Nós, gestores, temos que dedicar parte do nosso trabalho para o desenvolvimento de novas formas de execução do trabalho. É uma de nossas atribuições. Sou responsável por uma equipe de 52 pessoas neste departamento. Muitas delas aqui executam o seu trabalho de maneira automática, sem nenhuma análise sobre aquilo que elas estão fazendo. Isso é muito ruim! Nas minhas reuniões com a equipe, procuro sempre enaltecer esse aspecto com todos, todos... E estou aberta a sugestões e críticas sobre a forma como as pessoas devem executar o seu trabalho. (G1)

[...] Quando faço o meu trabalho, penso em como ele está relacionado ao negócio e às estratégias do banco... Como Gerente Pessoa Jurídica, meu trabalho é fechar parcerias com empresas oferecendo toda a gama de serviços bancários a elas. Toda empresa precisa de um banco. Uma pessoa pode ou não precisar de um serviço bancário, mas uma empresa constituída formalmente precisa de um banco. Uma das estratégias da organização é fomentar parcerias com o maior número possível de empresas, independentemente de seu tamanho ou faturamento... Acho que poderíamos tratar empresas diferentes de formas diferentes, mas hoje o banco dispensa a mesma atenção para uma empresa pequena que fatura $\mathrm{R} \$ 5 \mathrm{mil} / \mathrm{mês}$ e para uma multinacional que fatura $\mathrm{R} \$ 50$ milhões/mês $(\mathrm{G} 2)$.

[...] Procuro fazer uma análise detalhada sobre toda a rotina e todos os processos de trabalho atuais. $\mathrm{O}$ objetivo dessa análise é eliminar algumas atividades desnecessárias ou adiar aquelas consideradas menos importantes e priorizar as ações tidas como mais relevantes ou com mais urgência pra serem entregues [...] (G3)

[...] Sim, analisando criticamente a execução do meu trabalho, consigo entendê-lo melhor, mas tenho que admitir que, muitas vezes, é difícil, muito difícil mesmo fazer essa reflexão porque várias atividades são operacionais e repetitivas e muito do que eu faço parece já estar no 'piloto automático'. Outra coisa, algumas diretrizes são impostas pela matriz, o que dificulta uma tentativa de mudança na forma de fazer as coisas $[\ldots](\mathrm{G} 4)$

[...] Sem dúvida é muito importante parar um pouco e pensar sobre aquilo que está sendo feito, se é possível fazer de um jeito diferente e mais produtivo, ou simplesmente não fazer mais porque não há sentido nenhum naquilo. Esse aspecto deveria ser mais explorado por todos, principalmente por nós, gerentes [...] (G5)

[...] Confesso que é difícil parar por alguns instantes e fazer uma reflexão sobre as formas de execução do trabalho. Além disso, a cobrança por produtividade e pelo atingimento de metas do banco fazem a gente trabalhar sem parar, direto, porém reconheço que é superimportante fazer essa reflexão. Os gerentes, principalmente, 
precisam dedicar uma parte maior de seu tempo pra isso, pra pensar, pra melhorar os processos internos. Acho que essa reflexão também poderia impactar os resultados do banco [...] (G6)

Pelas falas dos gerentes entrevistados, é possível observar a importância da reflexão intrínseca e extrínseca no desempenho da atividade gerencial para o desenvolvimento de competências, mesmo quando as pressões do ambiente de trabalho não favorecem tais estratégias de aprendizagem.

\subsection{A Relação entre as Estratégias de Aprendizagem Informal e o Desenvolvimento de Competências Gerenciais}

A aprendizagem implica mudar conhecimentos, habilidades e atitudes, podendo promover o desenvolvimento de competências profissionais. Uma nova competência revela, inexoravelmente, que a pessoa aprendeu algo novo porque mudou sua forma de atuar (FREITAS; BRANDÃO, 2006; GIANSANTE; COSTA; VIEIRA; DUTRA, 2015).

Como o desenvolvimento de competências acontece por meio da aprendizagem, criar novas formas de fornecer oportunidades e experiências de aprendizagem constitui grande desafio para as organizações, principalmente porque a complexidade do ambiente organizacional faz surgir diversificadas demandas de competências, aumentando a distância entre o que as pessoas sabem e o que elas precisam aprender (POZO, 1999).

Os participantes desta pesquisa usaram também estratégias de aprendizagem informal no desenvolvimento de suas competências gerenciais. As competências gerenciais consideradas fundamentais pelos participantes da pesquisa foram a necessidade de se conhecer produtos e serviços oferecidos pelo banco (habilidades técnicas e conceituais) e relações interpessoais de qualidade (cortesia, presteza, educação e ética) com colegas de trabalho e clientes (habilidades humanas).

Os participantes desta pesquisa ressaltam que aprenderam a gerenciar a partir de experiências profissionais anteriores ao exercício da função gerencial (aplicação prática e reprodução) e experiências gerenciais advindas da interação com colegas de mesmo nível hierárquico (ajuda interpessoal). $\mathrm{Na}$ interação com os pares, ocorreu o desenvolvimento de conhecimentos, como a visão global da empresa e do setor, das outras unidades do banco e relativos ao próprio trabalho (habilidades técnicas e 
conceituais). Trabalhar com outras pessoas favorece observar e ouvir profissionais diferentes, ter contato com pontos de vista diversos e obter conhecimentos, não só explícitos, como tácitos. A interação com clientes é também apontada como fonte de desenvolvimento de competências gerenciais. Os gerentes afirmam nos seus depoimentos que esse tipo de interação contribuiu para o gerenciamento da sua unidade de acordo com as necessidades dos clientes (internos e externos), favorecendo o desenvolvimento de competências comportamentais como negociação, comunicação e relacionamento em geral (habilidades humanas).

As entrevistas realizadas indicam que as relações entre estratégias de aprendizagem e desenvolvimento de competências gerenciais são ponderadas da seguinte maneira: a percepção dos gerentes sobre sua carga de trabalho minimiza os efeitos da estratégia reflexão extrínseca e intrínseca sobre as habilidades técnicas e conceituais, e maximiza o efeito da estratégia ajuda interpessoal/interação e colaboração, por consequência, aprimorando as habilidades humanas. Todavia, é possível inferir, pelos relatos das entrevistas, que a reflexão extrínseca e a intrínseca têm forte impacto sobre as competências gerenciais, à medida que a percepção coletiva dos gerentes sobre as "melhores práticas de gestão" caminha para essa direção.

\subsection{Gerentes de Diferentes Áreas: Mesmas Estratégias de Aprendizagem Informal?}

Um dos objetivos desta pesquisa foi verificar se gerentes de diferentes áreas da mesma instituição financeira pública utilizam as mesmas estratégias de aprendizagem informal no trabalho, resultando no desenvolvimento de competências gerenciais. Dos seis gerentes entrevistados, são gerentes relacionados à Pessoa Jurídica G1, G2 e G6. Os participantes da pesquisa G3 e G4 trabalham como gerentes Pessoa Física. O gerente G5 atua na área comercial do banco, identificando oportunidades de novos negócios por meio do levantamento de informações sobre o mercado.

Três dos seis gerentes trabalham em agências bancárias (G2, G3 e G4). Os outros gerentes (G1, G5 e G6) atuam em departamentos do banco. A gerente G1, por exemplo, trabalha em uma Centralizadora Nacional de Manutenção de Créditos Comerciais e Rurais, uma espécie de escritório central do banco. O fato de os gerentes G1, G5 e G6 trabalharem em áreas estratégicas da organização (departamentos centrais) 
faz que seus locais de trabalho sejam distintos em relação às agências bancárias. Tal característica parece ter uma influência fundamental na maneira pela qual os gerentes G1, G5 e G6 priorizam estratégias de aprendizagem diferentes daquelas adotadas pelos demais gerentes entrevistados em agências bancárias, conforme já apresentado nas falas anteriores.

Os gerentes G1, G5 e G6 citaram a ajuda em material escrito como sendo sua principal fonte de informação para a realização do seu trabalho. Isso pode ser atribuído ao fato de os gerentes não terem colegas de trabalho com o mesmo nível hierárquico e mesmas atribuições funcionais em seus departamentos. Os gerentes G1, G5 e G6 também incluem a experiência anterior e o conhecimento adquirido ao longo da carreira no banco como uma das principais estratégias de aprendizagem.

Porém, os gerentes G2, G3 e G4, embora reconheçam a importância do material escrito como fonte de informação, priorizam a ajuda interpessoal ou a interação e colaboração de seus pares, uma vez que enfrentam ambientes hostis nas agências bancárias (pressões para o atingimento de metas e escassez de tempo) para uma leitura adequada do material escrito disponível pela Matriz do banco.

Os seis participantes da pesquisa afirmam conseguir analisar criticamente a execução de seus trabalhos e os impactos causados por eles à organização como um todo, ou seja, as reflexões intrínseca e extrínseca são estratégias de aprendizagem empregadas por todos os gestores. Aqui, cabe uma observação: embora os gerentes confirmem a adoção de tais estratégias, eles admitem ter dificuldade para utilizá-las, pois muitas de suas atividades desempenhadas são operacionais e repetitivas, além disso, a matriz do banco impõe diretrizes que devem ser seguidas por todos, sem questionamento. A reprodução, então, emerge como uma estratégia de aprendizagem que pode ser considerada válida (SILVA; VIEIRA; KUBO; BISPO, 2015).

\section{CONSIDERAÇÕES FINAIS}

O presente estudo buscou identificar as estratégias de aprendizagem informal no trabalho e a sua relação com o desenvolvimento de competências gerenciais em uma instituição financeira pública.

Os resultados sinalizam que as estratégias de aprendizagem informal contribuem para o desenvolvimento de competências gerenciais. A busca por ajuda em material 
escrito contribui para o aprimoramento das habilidades técnicas ou funcionais. A interação com colegas com o mesmo nível hierárquico, além de aperfeiçoar o conhecimento técnico dos gerentes entrevistados, desempenha um papel fundamental para o desenvolvimento de competências comportamentais. A interação com clientes internos e externos também merece destaque nesse sentido. A experiência anterior, o conhecimento adquirido ao longo da carreira profissional e as reflexões intrínseca e extrínseca são estratégias largamente utilizadas pelos gerentes investigados e que favorecem o aprimoramento das habilidades técnicas, humanas e conceituais.

Além disso, é importante destacar que o local de trabalho parece ter uma influência fundamental na maneira pela qual os gerentes aprendem. Os gerentes que trabalham em departamentos centrais da organização priorizam a ajuda em material escrito como estratégia de aprendizagem informal. Os gerentes que trabalham em agências bancárias, por sua vez, enfatizam a ajuda interpessoal ou a interação e colaboração de seus pares como principal estratégia de aprendizagem informal. Isso pode ser explicado pelo fato de que os gerentes que trabalham em departamentos não têm colegas de trabalho com o mesmo nível hierárquico e mesmas atribuições funcionais, dificultando, dessa forma, a interação com outros colegas de trabalho. Já em agências bancárias, onde as pressões para o atingimento de metas e escassez de tempo são características preponderantes, os gerentes acabam recorrendo aos colegas mais próximos, com funções semelhantes, para solucionar problemas, dúvidas e tomar decisões.

Acredita-se que os objetivos propostos para o presente trabalho tenham sido atingidos, enquanto estudo de caráter exploratório. Espera-se que os resultados apresentados possam contribuir de alguma forma, para um maior embasamento conceitual da área temática, seja pela utilização de uma abordagem inovadora, ou ainda, pela questão da complementaridade de estudos realizados nessa área.

Finalmente, destaca-se como limitação do estudo, o fato de a pesquisa não ter investigado um número maior de gerentes, envolvendo outras áreas da empresa em questão. Por ser uma organização de abrangência territorial nacional, para estudos futuros, sugere-se a investigação em outras localidades, no intuito de conferir uma melhor compreensão sobre o peso das diferenças regionais nas estratégias de aprendizagem e sua relação com o desenvolvimento de competências gerenciais. Além disso, recomenda-se que, em pesquisas futuras, sejam contempladas instituições 
financeiras privadas com o propósito de comparação com dados obtidos em instituições financeiras públicas.

\section{REFERÊNCIAS}

ANTONELLO, C. S. Saberes no singular? A falsa fronteira entre aprendizagem formal e informal. In: ANTONELLO, C. S.; GODOY, A. S. (Orgs.). Aprendizagem organizacional no Brasil. Porto Alegre: Bookman, 2011, p. 225-245.

BARDIN, L. Análise de Conteúdo. Lisboa: Edições 70, 1977.

BITENCOURT, C. C. A gestão de competências gerenciais e a contribuição da aprendizagem organizacional. Revista de Administração de Empresas, v. 44, n. 1, p. 58-69, 2004.

BITENCOURT, C. C. Gestão de competências e aprendizagem nas organizações. São Leopoldo (RS): Editora Unisinos, 2005.

BITENCOURT, C. C.; MOURA, M. C. C. A articulação entre estratégia e o desenvolvimento de competências gerenciais. Revista de Administração de Empresas, v. 5, n. 1, Art. 3, 2006.

BLOOM, B. S.; ENGELHART, M. D.; FURST, E. J.; HILL, W. H.; KRATHWOHL, D. R. Taxonomia de objetivos educacionais: domínio cognitivo. Porto Alegre: Globo, 1979.

BOWDITCH, J. L.; BUONO, A. F. Elementos do comportamento organizacional.São Paulo: Pioneira, 1992.

BRANDÃO, H. P. Aprendizagem, contexto, competência e desempenho: um estudo multinível. Tese de Doutorado. Brasília: Universidade de Brasília, Instituto de Psicologia, 2009.

BRANDÃO, H. P.; BORGES-ANDRADE, J. E. Causas e efeitos da expressão de competências no trabalho: para entender melhor a noção de competência. Revista de Administração Mackenzie, v. 8, n. 3, p. 32-49, 2007.

BRUNO-FARIA, M. F.; BRANDÃO, H. P. Competências relevantes a profissionais da área de T\&D de uma organização pública do Distrito Federal. Revista de

Administração Contemporânea, v. 7, n. 3, p. 35-56, 2003.

CARBONE, P. P.; BRANDÃO, H. P.; LEITE, J. B.; VILHENA, R. M. Gestão por competências e gestão do conhecimento. Rio de Janeiro: Ed. Fundação Getúlio Vargas, Série Gestão de Pessoas, 2005.

CONTE, D. L.; BIDO, D. S.; GODOY, A. S. Estratégias de Aprendizagem Informal de Enfermeiros. In: Encontro da Associação Nacional de Pós-Graduação e Pesquisa em 
Administração - EnANPAD, 35, 2011, Rio de Janeiro. Anais... Rio de Janeiro: ANPAD, 2011.

DURAND, T. L'alchimie de la competénce. Revue Française de Gestion, v. 127, n. 1, p. 84-102, 2000.

FLEURY, A.; FLEURY, M. T. Estratégias empresariais e formação de competências: um quebra-cabeça caleidoscópico da indústria brasileira. São Paulo: Atlas, 2001.

FREITAS, I. A.; BRANDÃO, H. P. Trilhas de aprendizagem como estratégia de TD\&E. In: BORGES-ANDRADE, J. E.; ABBAD, G.; MOURÃO, L. (Orgs.). Treinamento, desenvolvimento e educação em organizações e trabalho: fundamentos para a gestão de pessoas.Porto Alegre: Artmed-Bookman, p. 97-113, 2006.

GAGNÉ, R. M. Learnable aspects of problem solving. Educational Psychologist, v. 5, n. 2, p. 84-92, 1980.

GAGNÉ, R. M.; BRIGGS, L. J.; WAGER, W. W. Principles of Instructional Design.Orlando, Florida: Holt, Rinehartand Winston, 1988.

GIANSANTE, C. C. B.; COSTA, L. V.; VIEIRA, A. M.; DUTRA, J. S. Competências Coletivas e Desempenho Coletivo: um Estudo Com Equipes de Gastronomia. Revista Alcance, v. 22, n. 4, p. 457-473, 2015.

GODOI, C. K.; MATTOS, P. L. C. L. Entrevista qualitativa: instrumento de pesquisa e evento dialógico. In: GODOI, C. K.; BANDEIRA-DE-MELLO, R.; SILVA, A. B. (Orgs.). Pesquisa Qualitativa em Estudos Organizacionais: Paradigmas, Estratégias e Métodos. São Paulo: Ed. Saraiva, p. 308-310, 2006.

GODOY, A. S. Estudo de Caso Qualitativo. In: GODOI, C. K.; SILVA, A. B.; BALSINI, C. P. V. (Orgs.). Pesquisa Qualitativa em Estudos Organizacionais: Paradigmas, Estratégias e Métodos. São Paulo: Ed. Saraiva, 2006, p. 133-136.

GONCZI, A. Competency-based learning: a dubious past - an assured future? In: BOUD, D.; GARRICK, J. (Orgs.). Understanding learning at work. London: Routledge, 1999, p. 180-194.

HOLMAN, D.; EPITROPAKI, O.; FERNIE, S. Understanding learning strategies in the workplace: a factor analytic investigation. Journal of Occupational and Organizational Psychology, v. 74, n. 5, p. 675-681, 2001.

LE BOTERF, G. Competénce et navigation professionnelle.Paris: Éditions d'Organisation, 1999.

MENDES, C. N. M.; VIEIRA, A. M.; OLIVA, E. C.Influência da Educação Corporativa sobre a Relação entre Aprendizagem e Carreira: Estudo em Uma Empresa de Transporte de Cargas. Revista da Faculdade de Administração e Economia - 
ReFAE, v. 6, p. 85-106, 2015.

MURRAY, P. Organizational learning, competencies, and firm performance: empirical observations. The Learning Organization, v. 10, n. 5, p. 305-316, 2003.

NONAKA, I.; TAKEUCHI, H. Criação de Conhecimento na Empresa. Rio de Janeiro: Campus, 1997.

ODERICH, C. Gestão de competências gerenciais: noções e processos de desenvolvimento. In: RUAS, R.; ANTONELLO, C.; BOFF, L. H. (Orgs.).

Aprendizagem organizacional e competências. Porto Alegre: Bookman, 2005, p. 88115.

PANTOJA, M. J. Estratégias de aprendizagem no trabalho e percepções de suporte à aprendizagem contínua: uma análise multinível. Tese de Doutorado não publicada. Brasília: Universidade de Brasília, Instituto de Psicologia, 2004.

PANTOJA, M. J.; BORGES-ANDRADE, J. E. Estratégias de Aprendizagem no Trabalho em Diferentes Ocupações Profissionais. RAC-Eletrônica, v.3, n.1, p.41-62, 2009.

POZO, J. I. Aprendizes e mestres: a nova cultura da aprendizagem.Porto Alegre: Artmed, 1999.

RIGNEY, J. W. Learning strategies: a theoretical perspective. In: O'NEILL, H. F. (Org.). Learning strategies. New York: Academic Press, 1978.

SANTOS, A. C. O uso do método Delphi na criação de um modelo de competências. Revista de Administração da USP, v. 36, n. 2, p. 25-32, 2001.

SILVA, E. C. A.; VIEIRA, A. M.; KUBO, E. K. M.; BISPO, M. S. Aprendizagem Organizacional no Setor Farmacêutico: uma Análise Multinível a Partir da Percepção dos Gestores. RACE: Revista de Administração, Contabilidade e Economia, v. 14, n. 3, p. 1.091-1.118, 2015.

SONNENTAG, S.; NIESSEN, C.; OHLY, S. Learning at work: training and development. In: COOPER, C. L.; ROBERTSON, I. T. (Orgs.). International review of industrial and organizational psychology. London: John Wiley and Sons, 2004, v. 19 , p. 249-289.

SPARROW, P.; BOGNANNO, M. Competency requirement forecasting: issues for international selection and assessment. In: MABEY, C.; ILES, P. (Orgs.). Managing learning. London: Routledge, 1994, p. 57-69.

SPENCER, L. M.; SPENCER, S. M. Competence at work: models for superior performance.New York: John Wiley and Sons, 1993.

USHIRO, E. J.; BIDO, D. S. Estratégias de Aprendizagem em Função da Finalidade Para o Aprendizado: um estudo com trabalhadores da linha de produção de uma 
empresa do ramo automotivo. Seminários em Administração - SemeAd, XII, 2014, São Paulo. Anais... São Paulo: FEA-USP.

VIEIRA, A. M.; RIVERA, D. P. B. A Hermenêutica no Campo Organizacional: duas possibilidades interpretativistas de pesquisa. Revista Brasileira de Gestão de Negócios, v. 14, n. 44, p. 261-273, 2012.

WARR, P.; ALLAN, C. Learning strategies and occupational training. In: COOPER, C. L.; ROBERTSON, I. T. (Orgs.). International review of industrial and organizational psychology, v. 13, p. 83-120. Chichester: Wiley, 1998.

WARR, P.; BUNCE, D. Trainee characteristics and outcomes of open learning. Personnel Psychology, v. 48, n. 2, p. 347-375, 1995.

WARR, P.; DOWNING, J. Learning strategies, learning anxiety and knowledge acquisition. British Journal of Psychology, v. 91, n. 3, p. 311-333, 2000.

ZARIFIAN, P. A gestão da e pela competência. In: Anais do Seminário educação profissional, trabalho e competências. Rio de Janeiro: Centro Internacional para a educação, trabalho e transferência de tecnologia, 1996. 